Cam iyonomer esaslı güncel restoratif materyallerin sağlam dentine olan bağlanma dayanımlarının değerlendirilmesi

\section{Evaluation of shear bond strengths of glass ionomerbased restorative materials to sound dentine}

\author{
Uzman Diş Hekimi Merve Yilmaz Güneş \\ Sivas Ağız Diş Sağlığı Merkezi, Sivas \\ Orcid ID: 0000-0001-9939-3243
}

\section{Doç. Dr. Hakan Göktürk}

Bolu Abant İzzet Baysal Üniversitesi, Diş Hekimliği Fakültesi, Endodonti AD, Bolu Orcid ID: 0000-0003-3824-2569

\section{Doç. Dr. Emine Şirin Karaarslan \\ Tokat Gaziosmanpaşa Üniversitesi, \\ Diş Hekimliği Fakültesi, \\ Restoratif Diş Tedavisi AD, Tokat \\ Orcid ID: 0000-0002-6298-2463}

Geliş tarihi: 16 Mart 2020

Kabul tarihi: 1 Aralık 2020

doi: 10.5505/yeditepe.2021.41961

\section{Yazışma adresi:}

Doç. Dr. Emine Şirin Karaarslan

Tokat Gaziosmanpaşa Üniversitesi,

Diş Hekimliği Fakültesi, Restoratif Diş Tedavisi AD.

Tokat

Tel: (0356) 21242 22-7428, 7020

E-posta: karaarslan.emine@gmail.com
ÖZET

Amaç: Çalışmamızın amacı cam iyonomer esaslı dolgu materyallerinin farklı adeziv sistemler kullanılarak termalsiklusla yaşlandırma sonrası sağlam dentine olan makaslama bağlanma dayanımlarını değerlendirmektir.

Yöntem: Çürük, çatlak ve kırığa sahip olmayan 120 adet insan daimi 3. molar dişinin okluzal mineleri su soğutması altında elmas separe ile kesildi ve dentin yüzeyi açığa çıkarıldı. Cam iyonomer esaslı dört restoratif materyal; Cam Karbomer (GCP Dental, vianen, The Netherlands), Equia Forte (GC Corporation, Tokyo, Japan), Giomer (Beautifil-II, Shofu Inc., Kyoto, Japan), Photac-Fil Quick (3M, ESPE, USA) silindirik şeffaf kalıplar (4 mm çap $\times 4 \mathrm{~mm}$ yükseklik) yardımıyla dentine adeziv uygulanmaksızın, iki aşamalı bir self etch (Clearfil SE Bond) adeziv ve etch\&rinse (Adper Single Bond) adeziv ile dentine yüzey ön işlemi yapıldıktan sonra uygulandı. 10000 termal döngüyle yapay olarak yaşlandırılan örneklerin üniversal test cihazı kullanarak, makaslama bağlanma dayanımı değerleri belirlendi.

Bulgular: Bağlanma dayanımına ait değişkenlerden cam iyonomer esaslı restoratif materyallerin farklıı̆ı bağlanma dayanımını anlamlı olarak etkilemiş̧ir $(p<0,05)$. Çalışmada en yüksek bağlanma dayanımı değeri giomer+self etch adeziv $(13,64 \pm 5,81 \mathrm{MPa})$ grubuna, en düşük değer Cam Karbomer+ etch\&rinse adeziv $(1,49 \pm 0,71 \mathrm{MPa})$ grubuna aittir.

Sonuçlar: Farklı adeziv sistemlerin YVCIS, Giomer, RMCIS'ın dentine bağlanma dayanımını geliştirdiği, Cam karbomer üzerinde olumlu etkisi olmadığı söylenebilir.

Anahtar kelimeler: Cam karbomer siman, YVCIS, Giomer, RMCIS, bağlanma dayanımı.

\section{ABSTRACT}

Aim: The aim of our study was to evaluate the shear bond strengths of the glass ionomer-based filler materials to the strong dentin by using different adhesive systems after thermocycling.

Materials and Methods: The occlusal enamels of 120 human permanent third molar teeth without caries, cracks and fractures were cut with diamond separe under water cooling. Four glass ionomer based restorative materials: Glass Carbomer (GCP Dental, vianen, The Netherlands), Equia Forte (GC Corporation, Tokyo, Japan), Giomer (Beautifil-II, Shofu Inc., Kyoto, Japan), Photac-Fil Quick (3M, ESPE, USA) were applied to the prepared dentin surfaces after the dentine surface pretreatment with a two-step self-etch (Clearfil SE Bond) adhesive, etch\&rinse (Adper Single Bond) adhesive, and without dentine adhesive. Then, the specimens were artificially aged with 10.000 thermal cycles. Shear bond strength values were determined by using the universal testing device.

Results: The difference of glass ionomer based restorative materials significantly affected the bond strength values $(p$ $<0.05$ ). While the highest bond strength value was showed in the Giomer + self-etch bond group $(13.64 \pm 5.81 \mathrm{MPa})$ and the lowest value was observed in the Carbomer + etch\&rinse 
bond group $(1,49 \pm 0,71 \mathrm{MPa})$.

Conclusion: It can be concluded that different adhesive systems improve the bond strength of YVCIS, Giomer, RM$\mathrm{CIS}$, but do not have a positive effect on Glass Carbomer. Key words: Glass carbomer cement, HVGIC, Giomer, RMCIS, bond strength.

\section{Giriş}

Diş çürüğünden korunmaya ve önlemeye yönelik çalışmalar son yıllarda önem kazanmasına rağmen diş çürüğü birçok hasta için hala önemli bir sorun teşkil etmektedir. Hastalarda tercih edilecek en uygun restoratif materyalin ne olduğu konusu ise birçok diş hekimi tarafından farklı yorumlanmaktadır.

Kompozitler estetik ve tatmin edici mekanik özelliklere sahip materyaller olmakla birlikte, uygulamaları sırasındaki yüksek teknik hassasiyet, neme duyarlıık ve remineralizasyon kapasiteleri olmaması sebebiyle çürük aktif bireylerde klinik başarılarının sınırlı olması gibi dezavantajlara sahiptirler. ${ }^{2}$ Cam iyonomer simanlar, diş dokularına kimyasal adezyon, florür salınımı, antikaryojenik özellik, düşük sitotoksisite ve biyouyumluluk gibi avantajlar gösteren son zamanlarda popülaritesi artan restoratif materyallerdir. ${ }^{3}$ Kısa çalışma zamanı, uzun sertleşme süresi, aşınma direnci, basma dayanımı, kırıma noktası gibi mekanik özelliklerinin düşük olması cam iyonomer simanların de-

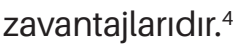

Cam iyonomer simanların dezavantajlarını gidermek; fiziksel, mekanik ve antibakteriyal özelliklerini geliştirmek için toz ve likitinde çeşitli modifikasyonlar yapılmıştır. ${ }^{5}$ Sertleşmenin erken aşamalarında Cis'ın nem hassasiyetini azaltmak, aşınma dirençlerini arttırmak ve çiğneme kuvvetlerine maruz kalan alanlarda kullanılmalarını sağlamak için, toz / sıvı oranı, partikül büyüklüğü ve dağııımı değiştirilerek materyal güçlendirilmiş ve yüksek viskoziteli cam iyonomer simanlar (YVCis) diş hekimliğinde kullanıma sunulmuştur. ${ }^{6}$ Bu doğrultuda ultra ince ve yüksek reaktif cam parçacıklarının cam iyonomer matriksinin içine karıştırılması sonucu elde edilen YVCis ve özel tasarlanmış karbomer doldurucu ve floroapatit/hidroksiapatit nanopartikül içeren cam iyonomer restoratif materyal olan Cam Karbomer Simanlar, cam iyonomer simanların dezavantajlarının üstesinden gelmek için geliştirilmiş materyallerdir. Ayrıca cam iyonomer siman ve rezin kompozit teknolojilerini birleştiren Rezin Modifiye Cam lyonomer Siman (RMCiS) ve Giomerler gibi hibrit materyaller de diş hekimliğinde kullanılan restoratif materyaller arasında yer almaktadır.?

Yüksek viskoziteli cam iyonomer simanların rezin kompozit ve amalgam alternatifi olmaları da amaçlandığı için geleneksel CiS'lardaki toz likit oranı 3:1 veya 4:1 iken; YVCis'da bu oranın 6:1 veya 7:1 olduğu bildirilmiştir. ${ }^{8} \mathrm{Hızlı}$ sertleşen ve estetik cam hibrit teknolojisinin geliştirilmiş bir ürünü olup YVCis materyali, kavitede yüzey hazırlığı ve adeziv uygulaması gerektirmez. Ayrıca dişlerin yaşından bağımsız tüm yüzeylere eşit derecede iyi bağlanır ve derin kavitelerde güvenle kullanılabilir. ${ }^{9}$

Estetik restoratif materyallerin uzun ömürlü klinik kullanımları için, florür salınımı ve reşarj yetenekleri önemlidir. Bu gereksinim göz önünde bulundurularak Shofu (Kyoto, Japan) firması tarafından diakrilik rezin kompozitlerle, cam iyonomer simanların özelliklerini birleştiren yeni bir hibrit materyal piyasaya sürülmüştür. Bu hibrit materyaller giomerler olarak isimlendirilmiştir. ${ }^{10}$ Giomerler, yüksek radyopasite, anti-plak etkisi, florür salınımı ve reşarj gibi avantajlarla bağlantılı olarak rezin kompozitlerin estetik ve fiziksel özelliklerini sergileyen adeziv restoratif materyaller grubudur. Bu hibrit estetik restoratif materyaller, önceden reaksiyona girmiş cam-iyonomer (PRG) teknolojisine dayanarak üretilir ve restoratif materyaldeki cam iyonomerlerin stabil fazını oluşturur. ${ }^{11}$ S-PRG doldurucu içeren malzemeler kısa süreli çalışmalarda üstün fiziksel özellikler ve zamanla artan florür salınımı ve mükemmel klinik performans göstermiştir. ${ }^{12}$ S-PRG materyali ayrıca, asitli tükürük sıvıları ile temas ettiğinde çevredeki ortamın pH'ını zayıf bir alkalin aralığına getiren bir tampon kapasitesine de sahiptir. ${ }^{13}$

Cam Karbomer Simanlar, GCP firması tarafından geliştirilen bir tür geleneksek cam iyonomerlerdir. Sertleşme reaksiyonu aköz polimerik asit ve iyon salabilen cam arasında gelişen asit-baz reaksiyonudur. Cam karbomer geleneksel Cis formülasyonunda bulunmayan bazı farklı materyaller de içermektedir. ${ }^{14}$ Karbomer ve floroapatit ile güçlendirilmiş cam iyonomer restoratif simanlardır. Çözünürlük, basınç, esneme dayanımını artırmak ve yüksek aşınmanın azaltılması amacıyla, özel tasarlanmış karbomer doldurucu ve floroapatit/hidroksiapatit nanopartikül içeren cam iyonomer restoratif materyaldir. ${ }^{15}$

Yapılacak bu in vitro çalışma ile dört farklı cam iyonomer esaslı restoratif materyallerin farklı adeziv sistemler kullanılarak termalsiklusla yaşlandırma sonrası sağlam dentine olan makaslama bağlanma dayanımlarının kıyaslanması hedeflenmiştir.

Çalışmamızın hipotezleri;

1. Çalışmada kullanılacak olan cam iyonomer esası materyallerin farklıığı makaslama bağlanma dayanımını etkilemeyecektir.

2. Çalışmada kullanılacak olan farklı adeziv uygulamaları makaslama bağlanma dayanımını anlamlı olarak etkilemeyecektir.

\section{GEREÇ ve YÖNTEM}

Bu çalışmada floroapatit/hidroksiapatit nanopartikül içerikli cam karbomer siman (GCP Dental), YVCIS (EQUIA Forte), giomer (Beautifil-II) ve RMCis (Photac Fil) olmak üzere dört adet cam iyonomer esaslı restoratif materyalin sağlam dentine olan makaslama bağlanma dayanımları karşılaştırıldı. 
Çalışmaya ait diğer değişkenler ise iki aşamalı total etch adeziv sistem (Adper Single Bond 2) ve iki aşamalı self etch adeziv sistem (Clearfil SE Bond) olmak üzere iki farklı adeziv sistemdir. Çalışmada kullanılan materyallere ait bilgiler Tablo 1'de yer almaktadır.

Tablo 1. Çalışmada kullanılan restoratif materyaller ve uygulama prosedürleri.

\begin{tabular}{|c|c|c|c|}
\hline $\begin{array}{c}\text { Materyalin } \\
\text { Adı }\end{array}$ & $\begin{array}{l}\text { Üretici } \\
\text { Firma }\end{array}$ & İçerik & Uygulama prosedürü \\
\hline $\begin{array}{l}\text { GCP Glass } \\
\text { Fill }\end{array}$ & $\begin{array}{l}\text { GCP Dental, } \\
\text { Vianen, } \\
\text { the } \\
\text { Netherlands }\end{array}$ & $\begin{array}{l}\text { Fuoro-aluminosilikat cam, apatit, } \\
\text { poliasitler }\end{array}$ & 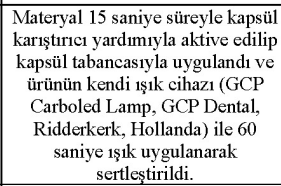 \\
\hline $\begin{array}{l}\text { EQUIA } \\
\text { Forte }\end{array}$ & $\begin{array}{c}\mathrm{GC} \\
\text { Corporation, } \\
\text { Tokyo, Japan }\end{array}$ & $\begin{array}{c}\text { Powder: fluoroaluminosilicate glass, } \\
\text { polyacrylic } \\
\text { acid, iron oxide } \\
\text { Liquid: polybasic carboxylic acid, } \\
\text { water }\end{array}$ & $\begin{array}{c}\text { Materyal 10 saniye süreyle kapsül } \\
\text { karıstrtrıc yardımılla aktive } \\
\text { edildikten sonra kapsül } \\
\text { tabancasiyla uygulandı. }\end{array}$ \\
\hline Beauttfil-II & $\begin{array}{l}\text { Shofu Inc., } \\
\text { Kyoto, Japan }\end{array}$ & $\begin{array}{c}\text { S-PRG doldurucu, } \\
\text { fluoroboroaliminosilikat cam, } \\
\text { BìS-GMA, TEGDMA, katalizör }\end{array}$ & $\begin{array}{c}\text { Giomer dolgu materyali, iki } \\
\text { tabaka }(2+2 \mathrm{~mm}) \text { halinde } \\
\text { uyguland; her bir tabakaya } 20 \mathrm{sn} \\
\text { polimerize edildi. }\end{array}$ \\
\hline Photac Fil & $\begin{array}{l}\text { 3M/ESPE, } \\
\text { Seefeld, } \\
\text { Germany }\end{array}$ & $\begin{array}{c}\text { PasteA: silanetreatedglass }(40-55 \%), \\
\text { silanetreatedzirconia( } 20-30 \%), \\
\text { PEGDMA (5-15\%), } \\
\text { silanetreatedsilica(5-15\%), } \\
\text { HEMA(1-15\%), glass } \\
\text { powder o5\%, BisGMA 05\%, } \\
\text { TEGMA o1\% } \\
\text { PasteB:silanetreatedceramic }(40- \\
\text { 60\%), copolymerofacrylicand } \\
\text { itaconic acid(20-30\%), water( } 10- \\
\text { 20\%), HEMA(1-10\%) }\end{array}$ & $\begin{array}{l}\text { Materyal } 10 \text { saniye süreyle kapsül } \\
\text { karıstrutc1 yardımıyla aktive } \\
\text { edildikten sonra kapsül } \\
\text { tabancasılla 2"şer mm'lik } \\
\text { tabakalar halinde uygulandi. Her } \\
\text { bir tabakaya } 20 \text { sn polimerize } \\
\text { edildi. }\end{array}$ \\
\hline $\begin{array}{l}\text { Adper Single } \\
\text { Bond } 2\end{array}$ & $\begin{array}{l}\text { 3MESPE, } \\
\text { MN, ABD }\end{array}$ & $\begin{array}{l}\text { Asit: \%37 fosforik asit, su, sentetik } \\
\text { amorf silika Bond: Etil alkol, Bis- } \\
\text { GMA, silanlanmıs silika, HEMA, } \\
\text { gliserol 1,3-dimetakrilat, diüretan } \\
\text { dimetakrilat, akrilik kopolimer ve } \\
\text { itaconik asit, EDMAB, UDMA, } \\
\text { difeniliodoniyum hekzaflorofosfat }\end{array}$ & $\begin{array}{l}\text { Asit uygulanır, } 15 \text { s beklendikten } \\
\text { sonra } 10 \text { s yikanır. Bond uygulanır, } \\
10 \text { s ı̧̧ ile polimerize edilir. }\end{array}$ \\
\hline $\begin{array}{l}\text { Clearfil SE } \\
\text { Bond }\end{array}$ & $\begin{array}{l}\text { Kuraray } \\
\text { Europe } \\
\text { GmbH, } \\
\text { Almanya }\end{array}$ & $\begin{array}{l}\text { Primer:10-MDP, HEMA, hidrofilik } \\
\text { dimetakrilat, kamforokinon, N,N- } \\
\text { dietanol-p-toluidin, su } \\
\text { Bond:10-MDP, BisGMA, HEMA, } \\
\text { N,N-dietanol-p-toluidin, silanlanmı̧ } \\
\text { kolloidal silika }\end{array}$ & $\begin{array}{l}\text { Primer uygulanir, 20s beklenir ve } \\
\text { hafif hava ile kurutulur. } \\
\text { Bond uygulanır, hafif hava ile } \\
\text { kurutulur. 10s beklendikten sonra } \\
\text { 10s şsı ile polimerize edilir. }\end{array}$ \\
\hline
\end{tabular}

\section{Test Örneklerinin Hazırlanışı}

Çalışmada; çürük, çatlak ve kırığa sahip olmayan 120 adet insan daimi 3. molar dişleri kullanıldı. Dişler periodontal aletlerle yumuşak doku debrislerinden iyice temizlenip distile suda yıkandıktan sonra 10 dakika boyunca sodyum hipoklorit solüsyonunda bekletildi.. ${ }^{16}$ Bu sekilde hazırlanan dişler en fazla 3 ay olmak üzere, fosfat tamponlu salin solüsyonunda saklandı. ${ }^{17}$ Dişlerin okluzal mineleri dentin yüzeyini açığa çıkarmak için horizontal olarak su soğutması altında elmas separe ile oklüzal yüzeylerindeki pitin en derin noktasına kadar kesildi. Plastik kalıplar yardımıyla otopolimerizan akriliğe (Meliodent, Heraeus Kulzer GmbH, Hanau, Germany) mine sement sınırının $1 \mathrm{~mm}$ altına kadar, oklüzal yüzeyler akrilik rezine paralel olacak şekilde gömüldü. Hazırlanan dentin yüzeyleri standart bir smear tabakası elde etmek için 600 gritlik silikon karbid kâğıdı ile cilalandı. Hazırlanan örnekler 24 saat süreyle $37^{\circ} \mathrm{C}$ distile suda bekletildikten sonra uygulanacak yüzey işlemi ve adeziv materyal türüne göre rastgele üç gruba ayrıldı. Daha sonra da her bir grup kullanılacak materyale göre dört gruba ayrıldı ( $n=10$ ) (Tablo 2).
Tablo 2. Calıșmada yer alan test gruplarının dağılımı.

\begin{tabular}{|c|c|c|c|}
\hline \multirow{2}{*}{ Materyal } & \multicolumn{3}{|c|}{ Yöntem } \\
\cline { 2 - 4 } & 1- Adeziv yok & 2- SE Bond & 3- Single Bond \\
\hline a: Cam Karbomer & $\mathrm{n}: 10$ & $\mathrm{n}: 10$ & $\mathrm{n}: 10$ \\
\hline b: YVCIS & $\mathrm{n}: 10$ & $\mathrm{n}: 10$ & $\mathrm{n}: 10$ \\
\hline c: Giomer & $\mathrm{n}: 10$ & $\mathrm{n}: 10$ & $\mathrm{n}: 10$ \\
\hline d: RMCIS & $\mathrm{n}: 10$ & $\mathrm{n}: 10$ & $\mathrm{n}: 10$ \\
\hline
\end{tabular}

\section{Restoratif Materyallerin Uygulanması}

Oluşturulan ilk grupta (adeziv uygulanmayan grup), dentine herhangi bir yüzey işlemi uygulanmaksızın silikon silindirik kalıplar (4 mm çap × 4 mm yükseklik) yardımıyla, restoratif materyaller üretici firma önerileri doğrultusunda dentin yüzeylerine uygulandı.

Çalışmanın 2. grubunda total etch adeziv sistem dentin yüzeylerine 15 saniye boyunca \%37'lik fosforik asit uygulaması yapıldıktan sonra yüzey yıkandı ve hava ile kurutuldu. Yapılan pürüzlendirme işleminin ardından bond üretici firma talimatlarına uyularak uygulandı. Daha sonra Cam iyonomer içerikli materyaller ilk gruptaki gibi dentin yüzeyine silindirik şeffaf kalıplar $(4 \mathrm{~mm}$ çap $\times 4 \mathrm{~mm}$ yükseklik) yardımıyla tatbik edildi.

Diğer çalışma grubunda (3. grupta) dentin yüzeylerine self etch adeziv sistem üretici firma talimatlarına uyularak uygulandı, materyaller önceki gruplarda belirtildiği gibi dentin yüzeyine tatbik edildi. Böylece 3 farklı yüzey hazırlama işlemi ve 4 farklı restoratif materyal olmak üzere toplamda 12 grupta 120 adet test örneği elde edildi. Hazırlanan örnekler $24 \mathrm{~s}$ süreyle $37^{\circ} \mathrm{C}^{\prime} \mathrm{de}$, distile su içinde etüvde (INB 200, Memmert GmBH, Almanya) bekletildi.

\section{Termalsiklus Uygulaması ve Makaslama Bağlanma Dayanımı Testi}

Hazırlanan örnekler ağız ortamını taklit eden $5 \pm 2{ }^{\circ} \mathrm{C}$ ve $55 \pm 2{ }^{\circ} \mathrm{C}$ sıcaklıktaki su banyosunda $30^{\prime}$ ar saniye ve 10 sn dışarıda bekletme süreleri olmak üzere termalsiklus cihazında (SD Mechatronik Thermocycler, SD Mechatronik GMBH, Westerham, Almanya) 10.000 kez tekrarlanan döngüyle yapay olarak yaşlandırıldı.

Makaslama bağlanma değerlerinin elde edilmesi amacıyla üniversal test cihazı (AGS-X Serisi masaüstü tipi, Schimadzu Europa $\mathrm{GmbH}$, Almanya) kullanıldı. Örneklerin cihaza sabit bir şekilde yerleştirilebilmesi için metal alaşımdan oluşan, vidalı bir sıkıştırma sistemine sahip bir düzenek kullanıldı. Test sırasında $0.5 \mathrm{~mm} / \mathrm{dk}$ hızda, bıçak ağzı şeklinde sonlanan bir uç, silindir şeklindeki cam iyonomer örneğiyle dik açı yapacak şekilde temas ederek kırılma gerçekleşinceye kadar kuvvet uygulanmıştır.

Cam iyonomer esaslı örneklerin dentin yüzeyinden kopma anlarındaki kuvvetler sistemin bağlı bulunduğu bilgisayarda Trapezium X 1.4.0 programı tarafından kaydedilip bağlanma yüzey alanına bölünerek hesaplandı (N/mm2). 


\section{İstatistiksel Analiz}

Çalışmada elde edilen bulgular hazır istatistik yazılımı ile hesaplandı (IBM SPSS Statistics 19, SPSSinc., an IBM Co.,Somers, NY). Makaslama testi uygulanan örneklerin dentin yüzey koşullarının değiştirilmesine göre bağlanma dayanımlarının karşılaşısıııması çift yönlü varyans analizi (ANOVA) ile değerlendirildi. Uygulanan restoratif materyallerin her bir yüzey koşuluna göre bağlanım dayanımlarının istatistiksel olarak çoklu karşılaştırııması Bonferonni düzeltmesi ile yapıldı. P değerleri 0.05 ten küçük olarak hesaplandığında istatistiksel olarak anlamlı kabul edildi.

\section{BULGULAR}

Çalışmada test gruplarına ait bağlanma dayanımı değerleri Tablo 4 'de belirtilmiştir $(p<0.05)$. Makaslama bağlanma dayanımına ait değişkenlerden restoratif materyallerin farklılığı bağlanma dayanımını anlamlı olarak etkilemiştir $(p=000)$. Aynı şekilde farklı adeziv uygulamaları da bağlanma dayanımını anlamlı etkilemiştir ( $p=0.04$ ) (Tablo 3). Tablo 3. ANOVA tablosu (iki yönlü varyans analizi).

\begin{tabular}{|c|c|c|c|c|c|}
\hline \multicolumn{7}{|c|}{ Bağımlı Değişken: Gerilme } \\
\hline Değişim kaynă̆ı & $\begin{array}{c}\text { Kareler } \\
\text { Toplamı }\end{array}$ & SD & $\begin{array}{c}\text { Kareler } \\
\text { Ortalaması }\end{array}$ & F & P \\
\hline Materyal & 1574.845 & 3 & 524.948 & 38.945 & .000 \\
\hline Adeziv sistem & 159.307 & 2 & 79.654 & 5.909 & .004 \\
\hline $\begin{array}{c}\text { Materyal * Adeziv } \\
\text { sistem }\end{array}$ & 395.372 & 5 & 79.074 & 5.866 & .000 \\
\hline
\end{tabular}

Çalışmamızda yapılan makaslama testi sonuçlarına göre en yüksek bağlanma değerleri self etch adeziv uygulanan giomer grubuna aittir (13.64 \pm 5.81$)$, en düşük bağlanma dayanımı Karbomer + etchধrinse adeziv grubunda izlen-

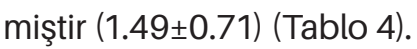

Tablo 4. İki faktöre göre makaslama bağlanma dayanımı dağılımı.

\begin{tabular}{|c|c|c|c|}
\hline \multirow{2}{*}{ Materyal } & \multicolumn{3}{|c|}{ Yöntem } \\
\cline { 2 - 4 } & Adeziv yok & SE Bond & Single Bond \\
\hline Cam Karbomer & $3.71 \pm 1.55(\mathrm{a}, \mathrm{x})$ & $3.17 \pm 1.28(\mathrm{a}, \mathrm{x})$ & $1.49 \pm 0.71(\mathrm{a}, \mathrm{x})$ \\
\hline YVCIS & $3.65 \pm 2.61(\mathrm{a}, \mathrm{xy})$ & $6.59 \pm 2.68(\mathrm{a}, \mathrm{x})$ & $1.5 \pm 0.89(\mathrm{a}, \mathrm{y})$ \\
\hline Giomer & ------- & $13.64 \pm 5.81(\mathrm{~b}, \mathrm{x})$ & $12.4 \pm 6.6(\mathrm{~b}, \mathrm{x})$ \\
\hline RMCIS & $5.3 \pm 4.01(\mathrm{a}, \mathrm{x})$ & $12.79 \pm 3.03(\mathrm{~b}, \mathrm{y})$ & $13.55 \pm 4.31(\mathrm{~b}, \mathrm{y})$ \\
\hline
\end{tabular}

Karbomer materyalinin adeziv uygulanmayan grubu ile uygulanan grupları arasında anlamlı fark bulunmamıştır ( $p>0.05$ ). Yine YVCiS materyalinin adeziv uygulanmayan grubu ile uygulanan grupları arasında anlamlı fark bulunmazken ( $p>0.05$ ), self etch adeziv ile total etch adeziv grupları arasındaki farklılık anlamlı düzeydedir $(p<0.05)$. Giomerin adeziv uygulanmayan grubunda herhangi bir bağlanma değeri tespit edilemezken, adeziv uygulanan grupları arasındaki farklılık anlamlı seviyede değildir ( $p>0.05$ ). RMCiS'in adeziv uygulanmayan grubu ile uygulanan gruplar arasında anlamlı farklılık gözlenirken $(p<0.05)$, farklı adeziv grupları arasında anlamlı farklılık izlenmemiştir ( $p>0.05$ ) (Tablo 4).
Cam Karbomer için en yüksek bağlanma dayanımı, adeziv uygulanmayan grupta; en düşük bağlanma dayanımı ise etch\&rinse grubunda tespit edilmiştir. YVCis materyali için en yüksek bağlanma dayanımı self etch adeziv grubunda; en düşük bağlanma dayanımı ise etch\&rinse grubunda izlenmiştir. Giomer için en yüksek bağlanma dayanımı self etch adeziv grubunda tespit edilmiştir. RMCiS için en yüksek bağlanma dayanımı total etch grubunda; en düşük bağlanma dayanımı adeziv uygulanmayan grupta tespit edilmiştir (Tablo 4).

\section{TARTIŞMA}

Çalışmamızda yeni teknolojilerle üretilen cam iyonomer esası restoratif materyallerin dentine bağlanmasının universal test cihazı ile makaslama testleri uygulanarak değerlendirilmesi, restoratif materyallerin dentine bağlanma dayanımının farklı adeziv sistemlerin etkilerinin değerlendirilmesiyle birlikte ölçülmesi hedeflenmiştir. Çalışmanın bulgularına dayanarak, cam iyonomer esaslı materyallerin farklıı̆ııın makaslama bağlanma dayanımını etkilemeyeceğini belirten birinci hipotez reddedilmiştir. Yine çalışmanın bulguları değerlendirildiğinde, farklı adeziv uygulamalarının da makaslama bağlanma dayanımını anlamlı etkilemeyeceğini belirten ikinci hipotez reddedilmiştir. Çünkü hem materyaller, hem de adezyon uygulamaları bağlanmayı anlamlı olarak etkilemiştir.

Laboratuar değerlendirmesi içeren in vitro test yöntemleri, klinik ortamı tam olarak simüle edemeseler de restorasyonlar üzerinde nem ve stres gibi çeşitli prosedürler (termal döngü gibi) aracılığıyla ağız boşluğu ortamını bir dereceye kadar taklit edebilirler. In vitro çalışmalarla elde edilen verilerin, oral kavitedeki karmaşık olaylar; nem ve sıcaklık değişimi gibi maruziyetlerden sonra elde edilen verilerle benzer olduğu bildirilmiştir. ${ }^{18,19}$ Bizim çalışmamızda da in vitro test yöntemleri kullanılmıştır.

Araştırmacılar, dentin derinliğinin arttıkça birim alandaki tübül sayısında ve genişliğindeki artışa bağlı olarak bağlanma dayanımının azaldığını bildirmişlerdir. ${ }^{20}$ Çalışmamızda cam iyonomer esaslı restoratif materyallerin bağlanma dayanımlarının dentin derinliğinden etkilenmemesi için yüzeyel dentin bölgesi kullanılmış bu sebeple dişler oklüzal mine dentin sınırının altından kesilmiştir.

Restoratif materyaller, dentinin mineye göre daha yüksek organik içeriği ve buna bağlı mineden daha düşük yüzey enerjisine sahip olması sebebiyle dentine daha zayıf bağlanmaktadırlar. ${ }^{21}$ Restoratif yaklaşımlarda diş dokusu ile sağlam bir bağlanma için tercih edilecek adeziv yöntem dentinal tabakaya göre seçilir. Güncel adeziv sistemler, total etch, self etch ve selektif etch sistemlerdir. Fosforik asitin kullanıldığı total etch sistem genelde mine yüzeyi için tavsiye edilirken dentin yüzeyi için de uygulanmakla birlikte agresif bir basamak olarak düşünülebilir. ${ }^{22}$ Dentine asit uygulanması, hibrit tabaka içindeki kollajen fibrillerin degredasyonuna yol açan matrix metalloproteinaz enzim- 
lerini aktive eder. ${ }^{23}$ Self etch teknolojisi ise asidik monomeri primerde içerir ve asitleme adımını gerektirmez. ${ }^{24} \mathrm{Ça-}$ lışmamızda cam iyonomer esaslı restoratif materyallerin dentin bağlanma dayanımınlarının değerlendirilmesinde total etch ve self etch adeziv sistemlerin etkinlikleri karşılaştırılmıştır.

Restoratif materyallerin dentine bağlanma etkinliğini ölçmek için günümüzde farklı yöntemler kullanılmaktadır. ${ }^{25}$ Bağlanma dayanımı bağlanan alanın büyüklüğüne bağlı olarak makro veya mikro test yöntemleriyle ölçülebilir. Makro bağlanma dayanımında bağlanma yüzey alanı $3 \mathrm{~mm}^{2}{ }^{2}$ den fazladır. ${ }^{25}$ Cam iyonomer simanlar gibi düşük bağlanma dayanımı gösteren materyallerde diğer testlere göre makro testlerin kullanımı daha kolay ve avantajlıdır.26 Bağlanma işleminden sonra başka numune prosedürü gerektirmediğinden, makaslama dayanımı testi en kolay ve hızı yöntem olması sebebiyle en popüler testtir. Bağlanma hakkında rapor veren bilimsel makalelerin \%26'sında kullanılmış olduğu bildirilmiştir. ${ }^{25}$ Çalışmamızda bağlanma dayanımını ölçmek için, makro makaslama testi kullanılmıştır.

In vitro çalışmalar alanında, dinamik stresleri yeniden üretebilen mevcut sistemlerin dışında, termal döngü uluslarası literatürde kabul edilen ve yaygın olarak kullanılan prosedürlerden biridir. Dental materyalleri termal döngüye dâhil eden birçok bilimsel çalışma yayınlanmıştır. ${ }^{27} \mathrm{Bu}$ sistem genel olarak, ağız boşluğunda meydana gelen termal değişimlerin taklit edilebilmesi için sıcak ve soğuk su banyolarında tekrarlanan döngüsel harekettir. Böylelikle restoratif materyallerin in vivo yaşlanmaları taklit edilmiş olur. ${ }^{28}$ Çalışmamızda örnekler ağız ortamını taklit eden $5 \pm 2{ }^{\circ} \mathrm{C}$ ve $55 \pm 2{ }^{\circ} \mathrm{C}$ sıcaklıktaki su banyosunda $30^{\prime}$ ar saniye ve 10sn dışarıda bekletme süreleri olmak üzere termalsiklus cihazında 10.000 kez tekrarlanan döngüyle yapay olarak yaşlandırılmıştır.

Giomerler sertleşme reaksiyonunda belirgin bir asit-baz reaksiyonu olmaksızın ışık aktivasyonuyla polimerize olan materyallerdir. ${ }^{29} \mathrm{Bu}$ materyalde flor-alumina silikat cam, polialkenoik asit ile suda reaksiyona girdikten sonra silika dolduruculu üretan, rezin içine katılır. S-PRG dolduru$\mathrm{cu}$ içeren materyallerin üstün fiziksel özellikleri vardır. ${ }^{30}$ Çalışmamızda gruplar arası ve grup içinde de en yüksek bağlanma dayanımı değeri giomer+ self etch adeziv grubunda (13.64 $\pm 5.81 \mathrm{MPa})$ bulunmuştur. Fakat Giomer+ total etch adeziv grubu (12.4 $\pm 6.6 \mathrm{MPa})$ ile aralarında anlamlı farklılık izlenmemiştir ( $p>0.05$ ). Bununla birlikte, adeziv sistem uygulanmayan giomer grubunda veri elde edilememiştir. Garcia ve ark.nın Giomerin mine ve orta derinlikli dentinde bağlanma dayanımını değerlendirdikleri çalışmalarında, değerlerin dentin için $3.3 \pm 1.2 \mathrm{MPa}$, mine için $5.5 \pm 2.7 \mathrm{MPa}$ olduğunu rapor etmişlerdir. ${ }^{31}$ Bir başka çalışmada, giomer esaslı materyalin dentine makaslama bağlanma dayanımı 12.39 \$1.05 MPa olarak bildirilmiş ve aynı çalışmada giomerin bağlanma dayanımı geleneksel cam iyonomerden $(7.76 \pm 1.07 \mathrm{MPa})$ daha yüksek bulunmuştur. ${ }^{32}$ Bu değer, çalışmamızda kullandığımız giomerin farklı adeziv sistemlerle kaydedilen bağlanma değerleriyle uyumludur. Giomerler çapraz bağlı polimer içeren bir ürün olup, önceden reaksiyona girmiş cam iyonomer (S-PRG) teknolojisine dayanarak üretilen hibrit estetik restoratif materyallerdir. Üretici firma giomer materyalinin rezin kompozit ve cam iyonomer simanların avantajlarını bize sunduğunu bildirmektedir. Aynı zamanda literatürde giomerlerin diş dokusuna adeziv sistemle uygulanması gerektiği rapor edilmiştir. ${ }^{33}$ Çalışmamızda kaydedilen adezivsiz grubun başarısızlığı giomerin rezin kompozit ve cam iyonomer simanların özelliklerini bir arada bulunduran hibrit yapısından kaynaklanmaktadır. Ayrıca adeziv sistem türleri bağlanma dayanımı değerlerini anlamlı ölçüde değiştirmemiştir.Cam Karbomer simanlar, cam iyonomer simanlara kıyasla daha yüksek cam oranına sahiptir. Bu materyal esasen geleneksel cam iyonomerlerde olduğu gibi asit-baz reaksiyonu ile sertleşen bir çeşit cam iyonomerdir. ${ }^{34}$ Cam iyonomerlerin rezin esaslı sistemlere göre mine ve dentine daha düşük bağlandıkları bilinmektedir. ${ }^{35}$ Bu nedenle çeşitli yüzey hazırlıkları yapılarak bağlanma kuvveti geliştirilmeye çalışılmaktadır.36,37 Ayar ve ark. tarafından 2017 yılında yapılan bir çalışmada mine ve dentin üzerinde geleneksel cis ve Cam Karbomerin makaslama bağlanma dayanımını değerlendiren çalışmada cam karbomerin, yüzey işlemi uygulanmaksızın mineye $(4.06 \pm 2.5 \mathrm{MPa})$ ve dentine $(2.19 \pm 2.1 \mathrm{MPa})$ bağlanma dayanımı, geleneksel cam iyonomerden (mine: $7.18 \pm 2.2$ MPa, dentin: $5.62 \pm 3.2 \mathrm{MPa})$ düşük bulunmuştur. ${ }^{38}$ Çalışmamızda total etch adeziv uygulanan Cam Karbomer grubunda $(1.49 \pm 0.71 \mathrm{MPa})$ tüm gruplar arası en düşük değer tespit edilmiştir. Cam karbomerde en yüksek bağlanma dayanımı adeziv uygulanmayan grupta (3.71 +1.55 MPa) izlenmiştir. Cam Karbomerin farklı adeziv sistemlerle uygulanması sonucunda elde edilen değerler arasında anlamlı fark bulunmazken self etch adeziv $(3.17 \pm 1.28 \mathrm{MPa})$ grubu etch\&rinse adeziv (1.49 $\pm 0.71 \mathrm{MPa})$ grubundan daha yüksek değerler göstermiştir. Çalışmamızda adeziv sistemlerle yüzey ön işlemi uygulanmasının Cam Karbomerin bağlanma dayanımında artışa neden olmadığı görülmüştür. Total etch adeziv sistemin kullanılması Cam Karbomerin bağlanma dayanımını azaltmıştır. Literatürde cam karbomerin adeziv sistemlerle dentine bağlanma dayanımını inceleyen bir çalışmaya rastlanmamıştır.

Estetik cam hibrit teknolojisiyle geliştirilmiş YVCiS'lar, geleneksel Cis'ların zayıf mekanik özelliklerini ve okluzal kuvvetler karşısındaki aşınma direncini arttırmayı amaçlamaktadırlar. ${ }^{39}$ Literatürde cam hibrit restorasyonların kompozit restorasyonlara göre kırılma dirençlerinin daha düşük olması hibritlerin yapısının daha katı ve sert olmasına dayandırılmaktadır. ${ }^{40}$ Bir çalışmada, geleneksel Cis’lara kıyasla 
daha üstün gerilme dayanıklıı̆ı beklenen YVCiS'ların benzer sonuçlar gösterdiği rapor edilmiştir. ${ }^{41}$ Bir başka klinik çalışmada araştııcılar, YVCis'ın klinik performansının sınıf I ve sınıf I| restorasyonlar için rezin kompozitle benzer olduğunu göstermiştir. ${ }^{42}$ Hasani ve ark. YVCis'nın dentine makaslama bağlanma değerini 500 termal döngü sonrası 2.33 $\pm 1.6 \mathrm{MPa}, 6000$ termal döngü sonrası $1.03 \pm 1.22$ MPa olarak bildirmişlerdir. ${ }^{43}$ Çalışmamızda kullandığımız YVCis'ın farklı adeziv sistemler kullanılarak termalsiklusla 10.000 döngü yaşlandırma sonrasında en yüksek bağlanma değeri self etch adeziv grubunda $(6,59 \pm 2,68 \mathrm{MPa})$ kaydedilmiş olup, adeziv uygulanmayan grupla anlamlı farklılık görülmemiştir $(3.65 \pm 2.61 \mathrm{MPa})$. Total etch adeziv sistem grubunda ise çok daha düşük bağlanma verileri elde edilmiştir. Bilindiği gibi çalışmada kullanılan YVCis, kavitede herhangi bir yüzey hazırlığı ve adeziv uygulaması gerektirmemektedir. Çalışmamızda adeziv uygulanan grupların her ikisinde de, Giomer ve RMCis'ın bağlanma değerleri birbirlerine yakın olup, YVCis ve Cam Karbomerden anlamlı derecede yüksek bulunmuştur. Bu durum, her iki materyalin rezin içeriği ve diş dokusuna bağlanma mekanizmalarıyla açıklanabilir.

RMCiS'ler diş dokularına kimyasal ve mikromekanik olmak üzere iki şekilde bağlanırlar. ${ }^{44}$ Choi ve ark tarafından yapılan sağlam ve etkilenmiş dentinde geleneksel cis ve RMCis'in mikro-çekme bağlanma dayanımını karşılaştırdıkları çalışmada, RMCis'in bağlanma dayanımının geleneksel CiS'ten yüksek olduğu rapor edilmiştir. ${ }^{45}$ Çaıışmamızda farklı yüzey koşullarında dentine bağlanma dayanımı değerlendirilen RMCiS için en yüksek bağlanma dayanımı total etch adeziv $(13.55 \pm 4.31 \mathrm{MPa})$ grubunda izlenmiş olup, self etch adeziv grubu $(12.79 \pm 3.03 \mathrm{MPa})$ ile anlamlı farklıık kaydedilmemiştir. Bu Cis için en düşük bağlanma dayanımı adeziv uygulanmayan $(5.3 \pm 4.01$ $\mathrm{MPa}$ ) grupta elde edilmiştir. Yüksek bağlanma değerleri veren çalışmaların birçoğunda yüzey işlemi uygulandığı belirtilmiştir.

\section{SONUÇLAR}

Çalışmanın koşul ve kısıtlamaları göz önüne alındığında yapılan değerlendirmeler aşağıdaki gibidir:

1. Makaslama bağlanma dayanımına ait değişkenlerden restoratif materyallerin ve adeziv sistemlerin farklılığı bağlanma dayanımını anlamlı olarak etkilemiştir.

2. Adeziv sistem uygulaması Cam Karbomerde bağlanma dayanımını azaltırken, iki aşamalı self etch adeziv uygulaması YVCis, Giomer ve RMCis gruplarında, total etch adeziv uygulaması ise RMCis'te bağlanma dayanımını arttırmıştır.

3. Çalışmamızda sağlam dentine olan makaslama bağlanma dayanımı değerlendirmesinde gruplar arası ve grup içinde de en yüksek bağlanma dayanımı değeri giomer+ iki aşamalı self-etch adeziv grubunda, en düşük bağlanma dayanımı Cam Karbomer+total etch adeziv grubunda kaydedilmiştir.

4. Farklı adeziv sistemlerin YVCis, Giomer, RMCiS'ın dentine bağlanma dayanımını geliştirdiği, Cam Karbomer üzerinde olumlu etkisi olmadığı söylenebilir.

\section{KAYNAKLAR}

1. Donly KJ, \& Segura A. Dental Materials. 4th ed., London: Elsevier Saunders; 2005.

2. Roulet JF. Benefits and disadvantages of tooth-coloured alternatives to amalgam. J Dent, 1997; 25: 459-473.

3. Kaya T, Tirali RE. Cam İyonomer Simanlardaki Gelişmeler. Atatürk Üniv Diş Hek Fak Derg, 2014; 23: 71-77.

4. McCabe JF. Applied Dental Materials, 9th Edition. New Jersey, Wiley Blackwell. 2008.

5. Najeeb S, Khurshid Z, Zafar MS, Khan AS, Zohaib S et. al. Modifications in Glass Ionomer Cements: Nano-Sized Fillers and Bioactive Nanoceramics. Int J Mol Sci, 2016; 17: $1134-1148$.

6. Friedl K, Hiller KA, Friedl KH. Clinical performance of a new glass ionomer based restoration system: a retrospective cohort study. Dent Mater, 2011;27:1031-1037.

7. Arora VBP. Giomer - A new hybrid aesthetic restorative material. J Conserv Dent, 2002; 5: 149-155.

8. Crowley CM, Doyle J, Towler MR, Hill RG, Hampshire S. The influence of capsule geometry and cement formulation on the apparent viscosity of dental cements. J Dent, 2006; 34: 566-573.

9.https://cdn.gceurope.com/v1/PID/equiaforte/leaflet/ LFL_EQUIA_Forte_en.pdf.

10. Sunico MC, Shinkai K, Katoh Y. Two-year clinical performance of occlusal and cervical giomer restorations. Oper Dent, 2005; 30: 282-289.

11. Gordan VV, Mondragon E, Watson RE, Garvan C, Mjör IA. A clinical evaluation of a self-etching primer and a giomer restorative material: Results at eight years. J Am Dent Assoc, 2007; 138: 621-627.

12. Gordan VV, Mjör IA, Vasquez $O$, Watson RE, Wilson N. Selfetching primer and resin-based restorative material: two-year clinical evaluation. J Esthet Restor Dent, 2002; 14: 296-302.

13. Featherstone JDB, Shields CP, Khademazad B, Oldershaw MD. Acid Reactivity of Carbonated Apatites with Strontium and Fluoride Substitutions. J Dent Res, 1983; 62: 1049-1053.

14. Cehreli SB, Tirali RE, Yalcinkaya Z, Cehreli ZC. Microleakage of newly developed glass carbomer cement in primary teeth. Eur J Dent, 2013; 7: 15-21.

15.https://interafricadental.com/wp-content/uploads/2016/10/Instructions-of-use-glass-fill-UK.pdf.

16. Potter JV, Zhu CF, McAlister T, Jones JD. Effects of pretreating preparations with sodium hypochlorite on bonding composite resin restorations. Gen Dent, 2013; 61:23-25.

17. Habelitz S, Marshall GW, Balooch M, Marshall SJ. Na- 
noindentation and storage of teeth. $\mathrm{J}$ of Biomechanics, 2002; 35: 995-998.

18. Morresi AL, D'Amario M, Capogreco M, Gatto R, Marzo $G$ et. al. Thermal cycling for restorative materials: Does a standardized protocol exist in laboratory testing? A literature review. J Mech Behav Biomed Mater, 2014, 29; 295-308.

19. Amaral FL, Colucci V, Palma-Dibb RG, Corona SA. Assessment of in vitro methods used to promote adhesive interface degradation: a critical review. J Esthet Restor Dent 2007;19(6):340-53.

20. Armstrong S, Breschi L, Özcan M, Pfefferkorn F, Ferrari $\mathrm{M}$, et. al. Academy of Dental Materials guidance on in vitro testing of dental composite bonding effectiveness to dentin/enamel using micro-tensile bond strength (囚TBS) approach. 2017, Dent Mater; 33: 133-143.

21. Garcia-Contreras R, Scougall-Vilchis RJ, Contreras-Bulnes $R$, Sakagami $H$, Morales-Luckie RA, et. al. Mechanical, antibacterial and bond strength properties of nano-titanium-enriched glass ionomer cement. J Appl Oral Sci, 2015; 23: 321-328.

22. Pashley DH, Tay FR, Breschi L, Tjäderhane L, Carvalho RM, et. al. State of the art etch-and-rinse adhesives. Dental Mater, 2011; 27:1-16.

23. Zhang S, \& Kern M. The Role of Host $囚$ derived Dentinal Matrix Metalloproteinases in Reducing Dentin Bonding of Resin Adhesives. Int J Oral Sci, 2009; 1: 163-176.

24. Van Meerbeek B, Yoshihara K, Yoshida Y, Mine A, De Munck J, et. al. State of the art of self-etch adhesives. Dental Mater, 2011; 27: 17-28.

25. Burke FJT, Hussain A, Nolan L, Fleming GJP. Methods used in dentine bonding tests: an analysis of 102 investigations on bond strength. Eur J Prosthodont Restor Dent, 2008; 16: 158-165.

26. Wang L, Sakai VT, Kawai ES, Buzalaf MA, Atta MT. Effect of adhesive systems associated with resin-modified glass ionomer cement. J Oral Rehabil, 2006; 33: 110-116. 27. D'Amario $M$, Campidoglio $M$, Morresi $A L$, Luciani $L$, Marchetti $E$, et. al. Effect of thermocycling on the bond strength between dual-cured resin cements and zirconium-oxide ceramics. J Oral Sci, 2010; 52: 425-430.

28. Özel Bektas Ö, Eren D, Herguner Siso S, Akin GE. Effect of thermocycling on the bond strength of composite resin to bur and laser treated composite resin. Lasers Med Sci, 2012; 27: 723-728.

29. Yap AUJ, Mok BYY. Surface Finish of a New Hybrid Aesthetic Restorative Material. Oper Dent, 2002; 27: 161166.

30. Ikemura K, Tay FR, Endo T, Pashley DH. A review of chemical-approach and ultramorphological studies on the development of fluoride-releasing dental adhesives comprising new prereacted glass ionomer (PRG) fillers. Dent Mater J, 2008; 27: 315-339.
31. Garcia RN, Alvarez AEG, Dias CE, Mazaro MA, Firmo T, et. al. Bond strength of contemporary restorative systems to enamel and dentin. RSBO, 2011; 8: 54-60.

32. Manuja N, Pandit IK, Srivastava N, Gugnani N, Nagpal R. Comparative evaluation of shear bond strength of various esthetic restorative materials to dentin: an in vitro study. J Indian Soc Pedod Prev Dent. 2011, 29: 7-13.

33. Deliperi S, Bardwell DN, Wegley C, Congiu MD. In-vitro evaluation of giomers microleakage after exposure to $33 \%$ hydrogen peroxide: Self etch and total-etch adhesives. Oper Dent 2006; 31: 227- 232.

34. Sidhu SK, Nicholson JWA. Review of Glass-Ionomer Cements for Clinical Dentistry. J Funct Biomater. 2016, 28;7(3).

35. Papacchini F, Goracci C, Sadek FT, Monticelli F, Garcia-Godoy F, et. al. Microtensile bond strength to ground enamel by glass-ionomers, resin-modified glass-ionomers, and resin composites used as pit and fissure sealants. J Dent, 2005, 33: 459-467.

36. Coutinho E, Cardoso MV, De Munck J, Neves AA, Van Landuyt $\mathrm{KL}$, et. al. Bonding effectiveness and interfacial characterization of a nano-filled resin-modified glass-ionomer. Dent Mater, 2009; 25: 1347-1357.

37. Hamama $\mathrm{H}$, Burrow M, Yiu C. Effect of dentine conditioning on adhesion of resin-modified glass ionomer adhesives. Aust Dent J, 2014; 59: 193-200.

38. Ayar K and Guven ME. Bond strength of glass carbomer material to enamel and dentin following different surface pretreatments. J Adhes Sci and Technol, 2017; 31: 1929-1937.

39. Gurgan S, Kutuk ZB, Ergin E, Oztas SS, Cakir FY. Four-year randomized clinical trial evaluate the clinical performarce of a glass ionomer restorative system. Oper Dent, 2015; 40: 134-143.

40. Narayanaswamy S, Meena N, Shetty A, Kumari A, Dn $N$. Finite element analysis of stress concentration in Class $\checkmark$ restorations of four groups of restorative materials in mandibular premolar. J Conserv Dent, 2008; 11: 121-126. 41. Fuhrmann D, Murchison D, Whipple S, Vandewalle K. Properties of New Glass-Ionomer Restorative Systems Marketed for Stress-Bearing Areas. Oper Dent, 2020; 45: 104-110.

42. Gurgan S, Kutuk ZB, Ergin E, Oztas SS, Cakir FY. Clinical performance of a glass ionomer restorative system: a 6-year evaluation. Clin Oral Investig, 2017; 21: 2335-2343. 43. Sheikh Hasani Y, Paryab M, Saffarpour A, Javad Kharazifard $M$, Shahrabi $M$. The Effect of Disinfection with Chlorhexidine on the Shear Bond Strength of Equia Resin-Modified Glass Ionomer Cement to Dentin in Permanent Teeth after Two Thermocycling Protocols. J Dent Shiraz Univ Med Sci, 2017; 18: 265-271.

44. Fritz UB, Finger WJ, Uno S. Resin-modified glass ionomer cements: Bonding to enamel and dentin. Dent Mater, 
1996; 12: 161-166.

45. Choi K, Oshida Y, Platt JA, Cochran MA, Matis BA, et. al. Microtensile Bond Strength of Glass Ionomer Cements to Artificially Created Carious Dentin. Oper Dent, 2006; 31: 590-597. 